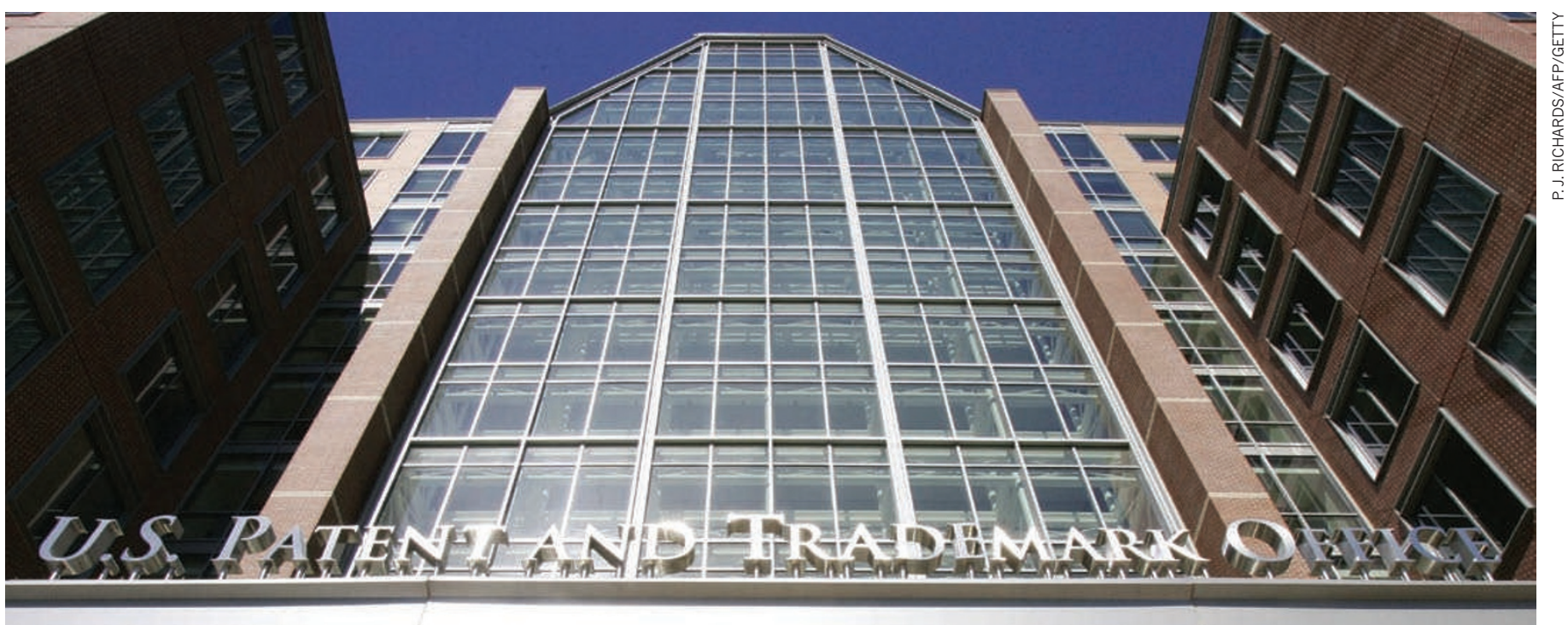

\title{
More for the research dollar
}

\section{Funders and universities should make the products of research more available - even if today's researchers pay a price, say Jeffrey L. Furman, Fiona Murray and Scott Stern.}

$\mathrm{O}$ n 29 October, the US government filed a brief stating that isolated but unmodified DNA should not be patented because merely isolating something does not turn it into a man-made product. This statement — submitted in a high-profile lawsuit over the validity of patents covering two genes linked to cancer - may or may not prevent the US Patent and Trademark Office adding new gene patents to the thousands already issued ${ }^{1}$. But the move has deepened the chasm between advocates of patenting research findings, and those calling for free and open access to publicly funded research.

The dispute over whether genes should be patented (or whether it is even legal to patent them) is typical of a wider debate. Researchers, open-source software designers, technology-transfer offices and entrepreneurs tend to fall into one of two camps with opposing opinions over whether patents, and intellectual-property rights over scientific findings, are 'good' or 'bad'.

Recent research in economics paints a far more complex picture. It suggests that scientific progress is not held up by intellectualproperty rights per se but by the short-sighted ways in which these rights are often managed. It is time for scientists, universities and, in particular, funding agencies to start acting on such findings.

The concept of 'governance' - the rules, expectations and practices through which people, organizations or resources are controlled - is as relevant to research institutions as it is to corporations. Thirty years ago this month, the Bayh-Dole Act altered the governance of science in the United States by replacing a confusing mass of rules over the ownership of patents with an overarching policy. The act gave universities - not funding agencies - the right to file and own intellectual property for inventions resulting from publicly funded research.

\section{SLOWING PROGRESS}

Economics is now beginning to shed light on the real-world effect of different governance schemes on scientific progress. Take a recent study ${ }^{2}$ by Heidi Williams from the National Bureau of Economic Research in Cambridge, Massachusetts. This shows that, in the race to sequence the human genome, the different approaches to intellectual-property management adopted by Celera Genomics, then in Rockville, Maryland, and the Human Genome Project had a dramatic effect on the rate of follow-on research.

In the late 1990s, Celera Genomics, headed by Craig Venter, used copyright law to limit access to the firm's gene-sequence data. By contrast, the US-government-funded Human Genome Project made its data available with minimal restrictions. Using indicators such as patents, numbers of papers published and commercially available diagnostic tests, Williams compared the rate of research associated with genes sequenced by Celera to that associated with genes sequenced by the Human Genome Project. She found that a diagnostic test was 30\% less likely to be developed for Celera-sequenced genes.

Another set of studies involving patents owned by Harvard University in Cambridge, Massachusetts, and the US chemicals company DuPont ${ }^{3,4}$ demonstrates how shifts in governance can enhance scientific and technological progress. In the 1990s, DuPont required academics and researchers working for other companies to sign complex licensing agreements to use or develop two technologies used in mouse genetic engineering - the company's Cre-lox recombinant technology and the OncoMouse (a mouse strain modified to carry a cancer-causing gene developed at Harvard and exclusively licensed to DuPont).

Harold Varmus, then director of the US National Institutes of Health, established an agreement with DuPont in the late 1990s that changed how the company's patents were managed ${ }^{5}$. Clear, simple licensing guidelines, and low-cost access to the mice enhanced follow-on research and prompted a burst of activity in novel areas. Mice strains derived from these technologies were cited at a $30 \%$ higher rate over expected levels for several years after the policy change ${ }^{4}$.

Other work suggests that restricting researchers' physical access to resources can be as damaging as doing so through contracts. For years, cell biology has been 
hampered by scientists storing cell lines independently. A recent study shows that the numbers of papers linked to 108 cell lines jumped more than $50 \%$ within 3 years of such lines being transferred to biological resource centres - such as the American Type Culture Collection in Manassas, Virginia ${ }^{6}$ (see 'The positive effect of access'). Thus, even when biomaterials are unencumbered by intellectual-property rights, making them accessible through a trusted, open-access resource centre increases their effect on research.

The challenge is to provide incentives for today's researchers to create and characterize novel materials, models and databases, while ensuring that tomorrow's researchers can access and use these resources to enhance their own productivity. We recommend, first, that scientists and policy-makers establish rules of practice that maximize the productivity of research in the long term - even if those rules cost today's researchers some inconvenience or loss of competitive edge. The data-sharing strategy used by sequencers of the human genome offers a striking example of the effectiveness of this type of long-range planning.

In 1996, those involved in sequencing the human genome, including the US National Institutes of Health and the UK Medical Research Council, introduced the Bermuda Rules. These essentially require publicly funded researchers to deposit their sequencing data on a daily basis. Where researchers once had a monopoly over their data for several months, they now have sole access for less than 24 hours. In the short term, sequencers are less able to extract private value from their work. The benefits to subsequent research generations, however, in being able to quickly and easily access new sequence data soon after it is generated, have been enormous.

\section{GREATER DISCLOSURE}

Our second recommendation is that as a default, licensing transactions resulting from publicly funded research be disclosed. The results of research are generally made accessible through publishing, but materials - such as cell lines or tissue samples - and licensing contracts can be extraordinarily hard to obtain. For instance, at least nine patents owned by eight different entities ${ }^{1}$ cover the PSEN2 gene for a membrane protein. Although the information regarding ownership of intellectual-property rights is published by the US Patent and Trademark Office, neither universities nor companies publicize which companies have licensing contracts with the patent owners.

To change this, funding agencies should insist that licensors report each transaction including the identity of licensees and, when feasible, the structure of the transaction $^{7}$. A standardized, accessible database of such transactions (managed perhaps

\section{THE POSITIVE EFFECT OF ACCESS}

The number of papers citing research on 108 cell lines rose rapidly after the cell lines were moved to a centralized, open-access culture collection. Data normalized by cell line, age of research and year of citation.

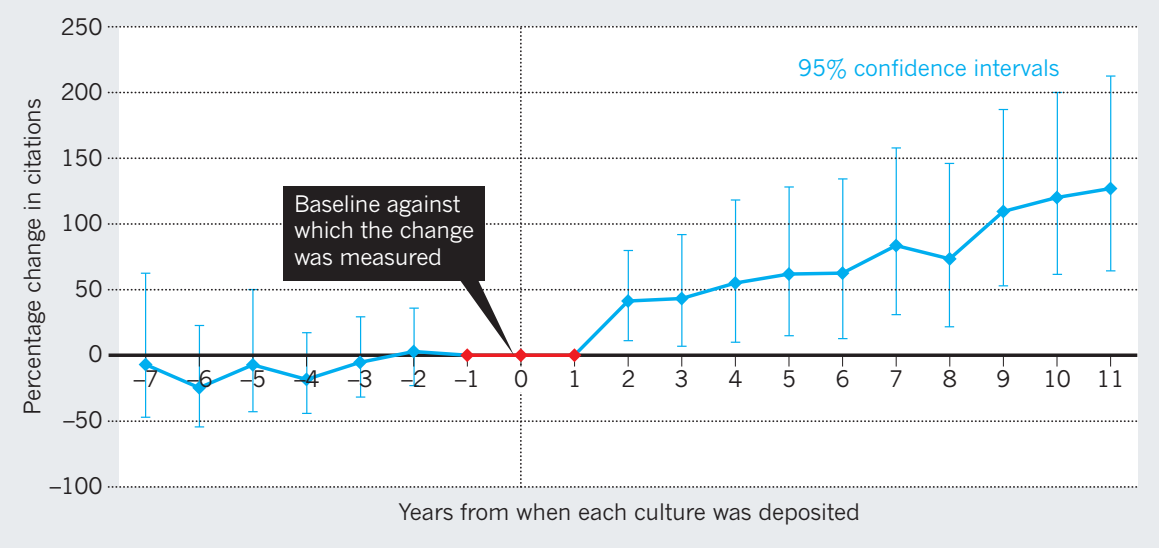

by the US National Science Foundation) would reduce future transaction costs for innovators trying to build on ideas with many different patented elements.

Third, licences and other access rules should be structured so as to enable further research by as diverse a group of scientists, innovators and entrepreneurs as possible. This does not happen for many resources. For example, roughly $60 \%$ of university licences are awarded exclusively to single companies ${ }^{8}$. This means that scientists at other institutions or companies invariably have to pay for, or are prohibited from using, particular ideas ${ }^{9}$. It also means that it is up to licensees whether others can use the university's intellectual property to develop novel applications, or make resulting products available to the widest set of users, including in developing countries.

The Bayh-Dole Act grants universities flexibility in shaping how intellectual-property rights are used, but most funders are passive in ensuring that such rights don't inhibit cumulative research. In the OncoMouse case, for instance, policy-makers reacted only after a decade of dispute. Some technology-transfer offices have tried to come up with standard language for transparent licensing agreements to ensure, for example, global access to ideas and to the products generated from them. Although not yet widely adopted by universities, such an approach provides a valuable starting point.

Encouraging the broadest possible use of resources must apply to physical access as well. Some well-intentioned foundations, such as the International Myeloma Foundation (IMF) in North Hollywood, California, have taken the lead in establishing crucial diseasespecific resources, including patient tissue samples. But, like the IMF, some foundations have granted only a select set of researchers access to the samples in the hope of attracting them to unique research opportunities. A better model is provided by the Coalition Against Major Diseases established by the Critical
Path Institute, in Tuscon, Arizona. In June this year, the members - including patient advocates, pharmaceutical companies, and various institutes and agencies - agreed to pool and share data from failed Alzheimer's disease clinical trials, thereby broadening access to otherwise proprietary data.

At a time when the public funding of science is under intense scrutiny, tremendous opportunity exists to establish policies that would greatly increase the impact of every dollar of research funding spent.

Jeffrey L. Furman is at the Boston University School of Management, Boston, Massachusetts 02215, USA. Fiona Murray is at the MIT Sloan School of Management, Cambridge, Massachusetts 02142, USA. Scott Stern is at the MIT Sloan School of Management, Cambridge, Massachusetts 02142, USA.

e-mail:fmurray@mit.edu

1. Jensen, K. \& Murray, F. Science 310, 239-240 (2005).

2. Williams, H. L. Intellectual Property Rights and Innovation: Evidence from the Human Genome NBER Working Paper 16213 (2010).

3. Murray, F. Am. J. Sociol. (in the press).

4. Murray, F., Aghion, P., Dewatripont, M., Kolev, J. \& Stern S. Of Mice and Academics: The Impact of Openness on Innovation NBER Working Paper 14819 (2009).

5. Smaglik, P. Nature 403, 350 (2000).

6. Furman, J. \& Stern S. Am. Econ. Rev. (in the press).

7. Lemley, M. A. \& Myhrvold, N. Hofstra Law Review $36,257-259$ (2007).

8. Shane, S. \& Somaya, D. J. Econ. Behav. Org. 63 , 739-755 (2007).

9. Chandrasekharan, S., Kumar, S., Valley, C. M. \& Rai, A. Nature Biotechnol. 2, 140-144 (2009).

\section{CORRECTION}

The Comment article 'Tar sands need solid science' (D. Schindler Nature $\mathbf{4 6 8}$ 499-501; 2010) stated that the $650 \mathrm{~km}^{2}$ footprint of the tar-sands mining is onehundredth the size of Alberta or Texas. It is one-thousandth the size of those areas. 